\title{
World Cancer Day 2021 - Perspectives in Pediatric and Adult Neuro-Oncology
}

\author{
Erik P. Sulman ${ }^{1,2,3,4^{*}}$ and David D. Eisenstat ${ }^{1,5,6,7^{*}}$ \\ 1 Section of Neuro-oncology \& Neurosurgical Oncology, Frontiers in Oncology and Frontiers in Neurology, Lausanne, \\ Switzerland, 2 Department of Radiation Oncology, NYU Grossman School of Medicine, New York, NY, United States, ${ }^{3}$ Brain \\ and Spine Tumor Center, Laura and Isaac Perlmutter Cancer Center, New York, NY, United States, ${ }^{4}$ NYU Langone Health, \\ New York, NY, United States, ${ }^{5}$ Children's Cancer Centre, Royal Children's Hospital, Parkville, VIC, Australia, ${ }^{6}$ Murdoch \\ Children's Research Institute, Parkville, VIC, Australia, ${ }^{7}$ Department of Paediatrics, University of Melbourne, Parkville, VIC, \\ Australia
}

OPEN ACCESS

Edited by:

Matthias Preusser,

Medical University of Vienna, Austria

Reviewed by:

Ann-Christin Hau,

Laboratoire National de Santé (LNS),

Luxembourg

Kamil Krystkiewicz,

10th Military Research Hospital and

Polyclinic, Poland

*Correspondence:

Erik P. Sulman

erik.sulman@nyulangone.org

David D. Eisenstat

david.eisenstat@rch.org.au

Specialty section: This article was submitted to Neuro-Oncology and Neurosurgical Oncology, a section of the journal

Frontiers in Oncology

Received: 28 January 2021 Accepted: 07 April 2021 Published: 10 May 2021

Citation: Sulman EP and Eisenstat DD (2021) World Cancer Day 2021 Perspectives in Pediatric and Adult Neuro-Oncology.

Front. Oncol. 11:659800. doi: 10.3389/fonc.2021.659800
Significant advances in our understanding of the molecular genetics of pediatric and adult brain tumors and the resulting rapid expansion of clinical molecular neuropathology have led to improvements in diagnostic accuracy and identified new targets for therapy. Moreover, there have been major improvements in all facets of clinical care, including imaging, surgery, radiation and supportive care. In selected cohorts of patients, targeted and immunotherapies have resulted in improved patient outcomes. Furthermore, adaptations to clinical trial design have facilitated our study of new agents and other therapeutic innovations. However, considerable work remains to be done towards extending survival for all patients with primary brain tumors, especially children and adults with diffuse midline gliomas harboring Histone H3 K27 mutations and adults with isocitrate dehydrogenase (IDH) wild-type, $\mathrm{O}^{6}$ guanine DNA-methyltransferase gene (MGMT) promoter unmethylated high grade gliomas. In addition to improvements in therapy and care, access to the advances in technology, such as particle radiation or biologic therapy, neuroimaging and molecular diagnostics in both developing and developed countries is needed to improve the outcome of patients with brain tumors.

Keywords: neuro-oncology, neurosurgical oncology, oncology, neurology, pediatrics

\section{INTRODUCTION}

If one could infer by attendance at major neuro-oncology conferences and the representation of pediatric and adult neuro-oncology at international oncology meetings, there has been an influx of new investigators, interest and significant advances in biomedical research pertaining to improving diagnosis, risk stratification, and treatment for children and adults with primary brain tumors. However, research progress has not yet had the anticipated impact on patient outcomes despite the promise. In the following article, we discuss several topics of current interest to the neuro-oncology community to reflect the directions the field is taking. 


\section{DIAGNOSTIC AND PROGNOSTIC CONSIDERATIONS}

The 2016 update to the World Health Organization (WHO) Classification of Tumours of the Central Nervous System brought important refinements, including but not limited to molecular genetic subgroups of medulloblastoma and the introduction of diffuse midline glioma with Histone H3 K27 mutations (1). With the advent and subsequent implementation of platforms such as whole genome sequencing (2), single cell nucleic acid sequencing $(3-7)$, nanostring technology $(8,9)$ and DNA methylation (10-12) profiling, some diagnostic categories have been replaced, such as the former primitive neuroepithelial tumor (PNET)grouping (13), whereas more common tumors such as low grade gliomas and glioblastoma (GBM) in pediatric and adult age groups are being split into subgroups specified by molecular and genetic considerations (14-20). The Glioma Longitudinal Analysis Consortium (GLASS) was established to assess genomic, epigenomic and other molecular changes such as tumor mutational burden and mutational signatures that occur over time from initial diagnosis to tumor progression/recurrence, including in response to chemotherapy and radiation $(19,21)$. Although driver mutations were retained at recurrence, prior therapies such as alkylating agents contributed to acquired mutations, including a hypermutator phenotype. Furthermore, selection of subclones with disease progression portended a worse prognosis (19). Other consortia, including the Consortium to Inform Molecular and Practical Approaches to CNS tumor Taxonomy (cIMPACT-NOW) $(22,23)$ have been organized to make further refinements that will be incorporated into the next edition of the WHO Classification.

Going forward, the task will be to prospectively study these subgroups in well designed clinical trials limited by smaller numbers of patients with these specific diagnoses. Significant pre-clinical and basic research is needed to identify actionable therapeutic targets within these subgroups. Furthermore, once appropriate therapies are identified, successful clinical trial accrual will likely require international collaboration given the limited patient numbers. However, many of these advanced molecular diagnostic technologies are not accessible in the developing world limiting the ability to both include these regions in trials and appropriately apply new treatments to the patients living there. Efforts to democratize molecular pathology using more widely available assays may be necessary, even at the cost of precision.

Other important advances include liquid biopsy for both initial diagnosis and at the time of progression/recurrence, such as for diffuse midline gliomas and to follow responses to therapy $(24,25)$. This is an important concept given the potential morbidity of repeated brain biopsy and the limitations of conventional magnetic resonance imaging (MRI). Challenges regarding the choice of cerebrospinal fluid (CSF), plasma, or serum, the technological platforms to utilize and which specific components (cell free DNA, RNA, microRNA, other noncoding RNAs, exosomes, tumor-educated platelets, etc.) remain as very active areas of investigation (26-28).
Repeat biopsy or tumor resection can be beneficial to the patient, including reduction of residual disease, assessment of acquired mutational profile and/or identification of new mutations (29). Timing of reoperation can influence the survival benefit and this should be factored into both retrospective and prospective studies (30). Reoperation may provide time to offer salvage therapies, including stereotactic radiosurgery, and assess their efficacy. However, the extent of re-resection is often limited by patient choice, the neuroanatomic location of the tumor and other considerations, such as risks of (further) neurological impairment, venous thromboembolism and/or other complications. Moreover, repeat biopsy may not provide sufficient tissue for full molecular genetic studies. Yet, this new data may inform the selection of available targeted therapies or enable the application of local therapies, such as oncolytic viruses, at the time of reoperation. The availability of additional genomic and epigenomic data includes the mutational signature associated with temozolomide and determination of tumor mutational burden (TMB). An increased TMB is one factor that may render the patient suitable for therapy with immune checkpoint inhibitors, discussed later in this Perspectives article. Furthermore, reoperation can facilitate eligibility to phase I/II clinical trials of novel targeted therapies or assessment of drug delivery and target inhibition in phase 0 or "window of opportunity" clinical trials (31).

Bioinformatic analyses of databases such as the Cancer Genome Atlas (TCGA) and the Chinese Glioma Genome Atlas (CGGA) have yielded numerous studies identifying novel prognostic and/or predictive biomarkers. However, many of these studies lack functional or clinical validation studies or have yet to be studied prospectively in clinical trials. Indeed, many of the molecular subgroups identified from these datasets reveal distinct biologies but are often defined by molecular techniques, such as whole transcriptome profiling, that are not readily applicable to the clinical setting.

\section{NEUROIMAGING AND NEUROSURGERY}

The use of chemoradiation and subsequently bevacizumab for adult GBM underscored the importance of identifying pseudoprogression and pseudoresponse, respectively. The Response Assessment in Neuro-Oncology (RANO) criteria $(32,33)$ and more recently iRANO (immunotherapy) (34) and RAPNO (pediatric) (35-37) working groups have standardized response assessments by neuroradiologists and other clinicians in the settings of both clinical trials and in the neuro-oncology clinic. These assessments have been particularly helpful in clinical trial design, but have less utility for the individual patient as the criteria often involve retrospective assignment of progression which is useful in determining the status of a clinical trial endpoint, but often too late to impact individual patient treatment.

The International Neuroimaging Data-sharing Initiative and others aim to streamline processing of MRI and other neuroimaging data across institutions following standard operating procedures for multi-institutional data sharing. These efforts are providing both neuroscientists and clinicians 
from less well-developed countries with access to advanced neuroimaging bioinformatics infrastructure, which can assist with diagnosis and assessment of responses to therapy (38-40). Collaborating approaches to develop segmentation algorithms (e.g. identifying areas of tumor or normal structures), such as the Federated Tumor Segmentation (FeTS) initiative (41), permit pooling of de-identified images and processing analysis tools to vastly improve upon what is possible from a single institution.

Furthermore, radiomics and the application of machine learning/artificial intelligence to diagnostic MRI scans has the potential to identify early tumor recurrence/progression, distinguish pseudoprogression from progression $(42,43)$ as well as to identify imaging signatures that are relatively specific to molecular subgroups of the more common diagnoses in adults (GBM, oligodendroglial tumors, low grade gliomas) $(44,45)$ and children (low grade gliomas, medulloblastoma, ependymoma, diffuse midline gliomas) $(46,47)$. While several techniques have been described, none have achieved widespread clinical acceptance for routine use. There remains a significant opportunity for those in the radiomics field to combine efforts and define standard, validated approaches to primary brain tumor imaging that can accurately predict tumor diagnosis as well as tumor progression. Once such radiomic collaboration to develop biomarkers of response is the Radiomics Signatures for Precision Diagnostics (ReSPOND) consortium (48) which, like the FeTS initiative, combines multiple institutional datasets to a much larger pool of data of over 3300 patients. Nevertheless, until these radiomic biomarkers achieve widespread clinical utilization, we are reliant on RANO criteria along with subjective clinical assessments.

Intraoperative MRI has the potential to increase the extent of resection and improve the delivery of local therapy, particularly when combined with direct intraoperative visualization techniques such as 5-aminolevulinic acid (5-ALA) fluorescence guided surgery $(49,50)$. Intraoperative stimulated Raman histology provides a real-time histologic analysis of tissue in under 60 seconds and can help direct the neurosurgeon, for example, to pursue additional biopsies or continue a more aggressive resection for a high-grade glioma $(51,52)$. Focused ultrasound can focally disrupt the blood brain barrier and also improve the provision of local therapies mediated by microbubbles $(53,54)$. Development of improved radiotracers for detection and/or therapy (theragnostic) of hypoxic, metabolic or specific molecular signatures by combined PET-CT and PETMR systems is a very active area of preclinical and clinical study for intra-axial and extra-axial tumors of the central nervous system. For example, ongoing studies of ${ }^{177} \mathrm{Lu}$-DOTATATE in meningioma have the potential to change the course of this disease at recurrence $(55,56)$ (NCT03971461).

\section{RADIATION ONCOLOGY}

Proton Beam Therapy (PBT), where available, has become the standard of care for some pediatric brain tumors, especially with the demonstration of improved outcomes with respect to hearing loss, neuroendocrinology and especially neurocognition (57-61). Craniospinal irradiation delivered via PBT has the advantages of relative sparing of the esophagus, bladder and bowel. However, although countries including the United Kingdom, Australia and Canada are planning to develop PBT in one or more sites, many developed countries currently lack dedicated proton therapy centers, so children and adults often have to travel very long distances to access this therapy (62). Furthermore, the place for PBT in adults, apart from generally accepted indications such as for chordomas, remains to be determined (63). There has been an observed trend to use PBT for low-grade and high-grade gliomas, the majority of which infiltrate into the surrounding brain parenchyma. Further study is warranted. Other forms of particle beam therapy, such as carbon ion therapy, are being evaluated in several countries for patients with meningiomas and gliomas and may have certain advantages over PBT, such as lower oxygen dependence (64).

Linear accelerators (LINAC) combined with onboard magnetic resonance imaging (MR/LINAC) units are increasing the precision of various radiation therapy modalities with the potential to reduce long-term sequelae. Moreover, these instruments allow for daily adaptation of treatments due to changes to tumor or normal anatomy or based on functional imaging data.

In the clinic, there has been a rising lower age limit to offer radiation to children and young adults with a brain tumor, respectively. Deferring or obviating the need for cranial irradiation in infants (less than 3 years) and young children (less than 10 years) is a very important consideration given the demonstrated impact of radiation on brain growth, development and cognition which continues through adolescence to young adulthood. However, it may be difficult to salvage patients with recurrent/progressive disease with radiation when it is not included in upfront therapies along with surgery and chemotherapy. Whenever possible, clinical trials accompanied by comprehensive neuropsychological and neurocognitive assessments are required when assessing the impact of reduced, delayed or omitted radiotherapy (65). For some patient populations, such as those with brain metastases, where therapeutic interventions often have limited impact on the patient's survival but serve an important palliative role, the use of functional, neurocognitive endpoints takes on a greater significance (66). In trials of glioma patients where intermediate endpoints of progression based are of limited benefit, neurocognitive changes may serve as an early indicator of patient survival (67).

Non-ionizing radiation, such as tumor treating fields (TTFields), has shown a survival benefit for patients with newly diagnosed GBM (68) and to be equivalent to salvage chemotherapy for patients with recurrent GBM (69). Ongoing trials to combine TTFields with standard and novel therapies are being conducted in both adult and pediatric patients with brain tumors. Despite these results, ongoing concerns raised by some in neuro-oncology has limited its widespread adoption (70). However, recent positive clinical trials in other disease sites only highlight the role of TTFields in the oncologic armamentarium (71). 


\section{CHEMOTHERAPY, TARGETED AND EPIGENETIC THERAPIES}

The standard of care for newly diagnosed adults with glioblastoma, especially those with MGMT promoter methylated tumors, remains chemoradiation with temozolomide followed by 6 to 12 cycles of adjuvant temozolomide (72). However, the neurooncology community is eagerly awaiting a significant advance, especially for those with IDH wild-type MGMT promoter unmethylated tumors. A recent meta-analysis assessed the prognostic value of various MGMT promoter methylation tests for predicting overall survival in temozolomide treated GBM patients. Although both pyrosequencing and methylation specific polymerase chain reaction were superior to immunohistochemistry, determination of ideal thresholds and which specific $\mathrm{CpG}$ sites to assess remain undetermined (73).

Furthermore, there is no consensus with respect to the sequence and selection of chemotherapy and/or targeted therapies for recurrent GBM. However, the recent introduction of IDH inhibitors in advanced gliomas has demonstrated the importance of identifying molecular subgroups that can benefit from targeted therapies (74). The identification of less common GBM molecular subgroups with fusions involving FGFR or the TRK family of neurotrophin receptors has been another promising advance leading to ongoing clinical trials using fibroblastic growth factor receptor (FGFR) or tropomyosin receptor kinase (TRK) inhibitors, respectively (75-77). Similarly, the use of v-Raf murine sarcoma viral oncogene homolog B (BRAF) inhibitors for tumors harboring BRAF V600E mutations, including pediatric low grade gliomas, gangliogliomas, pleiomorphic xanthoastrocytomas and Langerhans Cell Histiocytosis, has extended survival for many of these patients (78). A novel approach targeting protein arginine methyltransferase 5 (PRMT5), including a brainpenetrant PRMT5 inhibitor, has shown promise in preclinical studies wherein a specific splicing signature in GBM may predict responses to this drug class in vitro and in vivo (79).

The demonstration that pilocytic astrocytomas are driven by MAPK signaling has resulted in the implementation of BRAF and/or MEK inhibitors at the time of initial diagnosis or at progression (78). However, similar to the treatment of recurrent GBM in adults, the timing, sequence and/or duration of the use of these targeted therapies in children requires further study in carefully designed clinical trials, including separate cohorts for patients with neurofibromatosis (NF) type 1 . The effect of longterm inhibition of MAPK signaling on normal growth and development of the child remains undetermined. Furthermore, there still remains a place for single agent or combination chemotherapy for these relatively common pediatric brain tumors.

Advances in our understanding of the molecular genetics of diffuse midline gliomas and high-grade gliomas in children have identified the coopting of neurodevelopmental pathways by these tumors and underscore the importance of harnessing epigeneticbased therapies, including but not limited to selected HDAC, bromodomain and other inhibitors (80-82). Posterior fossa type A (PFA) ependymomas $(83,84)$ also demonstrate loss of Histone H3
K27 trimethylation and may benefit from the implementation of these treatments. Challenges are considerable, including tumor specificity, and international cooperative groups are focused on early phase clinical trials to identify promising agents to advance to larger patient cohorts.

\section{CLINICAL TRIAL DESIGN}

As former diagnostic categories are parsed into subgroups based upon molecular genetic and other diagnostic considerations, the field of neuro-oncology continues to explore other types of clinical trial design. These include basket trials where several diagnostic entities sharing the same mutational profile or target are grouped. Umbrella trials or master protocols allow larger groups of patients, for example adult GBM, to be enrolled in concurrent and/or sequential smaller phase II trials as part of one very large study that can more efficiently assess the efficacy of novel, often targeted therapies, either at diagnosis or at the time of tumor progression. Adaptive, Bayesian and other innovative clinical trial designs that optimize patient eligibility or use data from prior clinical trials are essential to rapidly translate progress from the basic laboratory to the clinic to improve patient outcomes (85-87). The ongoing Adaptive Global Innovative Learning Environment for Glioblastoma (GBM AGILE) trial combines adaptive trial design with a registration expansion cohort for rapid evaluation of candidate therapeutics and regulatory approval while minimizing the required patient sample size (88). A unique feature of GBM AGILE is the direct incorporation of molecular classification (namely MGMT promoter methylation status) into the trial and the potential for incorporation of treatment-specific predictive molecular biomarkers. This type of adaptive trial is a model which is applicable across neuro-oncology.

\section{IMMUNO-ONCOLOGY}

It has been a very exciting time for innovative approaches using several types of therapy that harness the immune system, either alone, in combination or added to standard therapies using chemotherapy or radiation therapy $(89,90)$. These approaches include tumor vaccines (91), oncolytic viruses (92-96), immune checkpoint inhibitors (97-99) and chimeric antigen receptor (CAR) T-cells (100-103). Improved clinical outcomes using immune checkpoint inhibitors in patients with biallelic mismatch repair deficiency and high tumor mutation burdens (TMB) have been reported (104). However, many pediatric and some adult brain tumors have low TMB and are highly immunosuppressive. Recent negative reports of phase III trials of immune checkpoint inhibitors in GBM highlights this challenge $(105,106)$. Moreover, the use of immunotherapies is complicated by the potential for intracranial inflammation which may result in significant morbidity or long-term complications. Treatment of inflammation using standard corticosteroid therapy can further compound the tumor immunosuppression and negate any benefit from immunotherapy. 
Other factors under active study include assessment of the immune tumor microenvironment and how modulating the tumor microenvironment may improve the efficacy of these immunotherapies. Moreover, the influence of the variably intact blood brain barrier and the unintended adverse consequences of immunotherapy, such as brain edema, aseptic meningitis, encephalitis, or peripheral neuropathies are also important considerations as this very promising area of therapy is further developed.

\section{AWARENESS, EQUITY, DIVERSITY AND INCLUSIVITY}

In both developed and developing countries there are initiatives to raise public awareness of brain tumors, including the HeadSmart program in the United Kingdom (107). Access to emerging diagnostic (genomic platforms, DNA methylation profiling, advanced imaging) and therapeutic options (targeted and immunotherapies, PBT) remains limited to some developed

\section{REFERENCES}

1. Louis DN, Perry A, Reifenberger G, von Deimling A, Figarella-Branger D, Cavenee WK, et al. The 2016 World Health Organization Classification of Tumors of the Central Nervous System: A Summary. Acta Neuropathol (2016) 131:803-20. doi: 10.1007/s00401-016-1545-1

2. Northcott PA, Buchhalter I, Morrissy AS, Hovestadt V, Weischenfeldt J, Ehrenberger T, et al. The Whole-Genome Landscape of Medulloblastoma Subtypes. Nature (2017) 547:311-7. doi: 10.1038/nature22973

3. Patel AP, Tirosh I, Trombetta JJ, Shalek AK, Gillespie SM, Wakimoto H, et al. Single-Cell RNA-seq Highlights Intratumoral Heterogeneity in Primary Glioblastoma. Science (2014) 344:1396-401. doi: 10.1126/ science. 1254257

4. Tirosh I, Venteicher AS, Hebert C, Escalante LE, Patel AP, Yizhak K, et al. Single-Cell RNA-seq Supports a Developmental Hierarchy in Human Oligodendroglioma. Nature (2016) 539:309-13. doi: 10.1038/nature20123

5. Venteicher AS, Tirosh I, Hebert C, Yizhak K, Neftel C, Filbin MG, et al. Decoupling Genetics, Lineages, and Microenvironment in IDH-mutant Gliomas by Single-Cell RNA-Seq. Science (2017) 355(6332):eaai8478. doi: $10.1126 /$ science.aai8478

6. Filbin MG, Tirosh I, Hovestadt V, Shaw ML, Escalante LE, Mathewson ND, et al. Developmental and Oncogenic Programs in H3K27M Gliomas Dissected by Single-Cell RNA-Seq. Science (2018) 360:331-5. doi: 10.1126/science.aao4750

7. Gojo J, Englinger B, Jiang L, Hubner JM, Shaw ML, Hack OA, et al. SingleCell RNA-Seq Reveals Cellular Hierarchies and Impaired Developmental Trajectories in Pediatric Ependymoma. Cancer Cell (2020) 38:44-59.e9. doi: 10.1016/j.ccell.2020.06.004

8. D'Arcy CE, Nobre LF, Arnaldo A, Ramaswamy V, Taylor MD, Naz-Hazrati L, et al. Immunohistochemical and Nanostring-Based Subgrouping of Clinical Medulloblastoma Samples. J Neuropathol Exp Neurol (2020) 79:437-47. doi: 10.1093/jnen/nlaa005

9. Ryall S, Arnoldo A, Sheth J, Singh SK, Hawkins C. Detecting Stem Cell Marker Expression Using the NanoString nCounter System. Methods Mol Biol (2019) 1869:57-67. doi: 10.1007/978-1-4939-8805-1_5

10. Capper D, Jones DTW, Sill M, Hovestadt V, Schrimpf D, Sturm D, et al. DNA Methylation-Based Classification of Central Nervous System Tumours. Nature (2018) 555:469-74. doi: 10.1038/nature26000

11. Capper D, Stichel D, Sahm F, Jones DTW, Schrimpf D, Sill M, et al. Practical Implementation of DNA Methylation and Copy-Number-Based CNS countries or specific tertiary/quaternary pediatric or comprehensive cancer centers leading the vanguard in neurooncology (108). Moreover, it will be challenging for health care systems or third-party insurers in many countries to ensure equitable access to these recent and emerging clinical advances.

\section{DATA AVAILABILITY STATEMENT}

The original contributions presented in the study are included in the article/supplementary material. Further inquiries can be directed to the corresponding authors.

\section{AUTHOR CONTRIBUTIONS}

This submission is a Perspective article for World Cancer Day 2021 submitted by DE and ES who equally contributed to the submission. All authors contributed to the article and approved the submitted version.
Tumor Diagnostics: The Heidelberg Experience. Acta Neuropathol (2018) 136:181-210. doi: 10.1007/s00401-018-1879-y

12. Pickles JC, Fairchild AR, Stone TJ, Brownlee L, Merve A, Yasin SA, et al. DNA Methylation-Based Profiling for Paediatric CNS Tumour Diagnosis and Treatment: A Population-Based Study. Lancet Child Adolesc Health (2020) 4:121-30. doi: 10.1016/\$2352-4642(19)30342-6

13. Sturm D, Orr BA, Toprak UH, Hovestadt V, Jones DTW, Capper D, et al. New Brain Tumor Entities Emerge From Molecular Classification of CNSPnets. Cell (2016) 164:1060-72. doi: 10.1158/1538-7445.AM2016-2696

14. Khuong-Quang DA, Buczkowicz P, Rakopoulos P, Liu XY, Fontebasso AM, Bouffet E, et al. K27M Mutation in Histone H3.3 Defines Clinically and Biologically Distinct Subgroups of Pediatric Diffuse Intrinsic Pontine Gliomas. Acta Neuropathol (2012) 124:439-47. doi: 10.1007/s00401-0120998-0

15. Schwartzentruber J, Korshunov A, Liu XY, Jones DT, Pfaff E, Jacob K, et al. Driver Mutations in Histone H3.3 and Chromatin Remodelling Genes in Paediatric Glioblastoma. Nature (2012) 482:226-31. doi: 10.1038/ nature10833

16. Clarke M, Mackay A, Ismer B, Pickles JC, Tatevossian RG, Newman S, et al Infant High-Grade Gliomas Comprise Multiple Subgroups Characterized by Novel Targetable Gene Fusions and Favorable Outcomes. Cancer Discov (2020) 10:942-63. doi: 10.1158/2159-8290.cd-19-1030

17. Ceccarelli M, Barthel FP, Malta TM, Sabedot TS, Salama SR, Murray BA, et al. Molecular Profiling Reveals Biologically Discrete Subsets and Pathways of Progression in Diffuse Glioma. Cell (2016) 164:550-63. doi: 10.1016/ j.cell.2015.12.028

18. Brennan CW, Verhaak RG, McKenna A, Campos B, Noushmehr H, Salama SR, et al. The Somatic Genomic Landscape of Glioblastoma. Cell (2013) 155:462-77. doi: 10.1016/j.cell.2013.09.034

19. Barthel FP, Johnson KC, Varn FS, Moskalik AD, Tanner G, Kocakavuk E, et al. Longitudinal Molecular Trajectories of Diffuse Glioma in Adults. Nature (2019) 576:112-20. doi: 10.1038/s41586-019-1775-1

20. Ryall S, Zapotocky M, Fukuoka K, Nobre L, Guerreiro Stucklin A, Bennett J, et al. Integrated Molecular and Clinical Analysis of 1,000 Pediatric Low-Grade Gliomas. Cancer Cell (2020) 37:569-83.e5. doi: 10.1016/j.ccell.2020.03.011

21. Consortium G. Glioma Through the Looking GLASS: Molecular Evolution of Diffuse Gliomas and the Glioma Longitudinal Analysis Consortium. Neuro Oncol (2018) 20:873-84. doi: 10.1093/neuonc/noy020

22. Louis DN, Aldape K, Brat DJ, Capper D, Ellison DW, Hawkins C, et al. cIMPACT-NOW (the Consortium to Inform Molecular and Practical 
Approaches to CNS Tumor Taxonomy): A New Initiative in Advancing Nervous System Tumor Classification. Brain Pathol (2017) 27:851-2. doi: 10.1111/bpa.12457

23. Louis DN, Giannini C, Capper D, Paulus W, Figarella-Branger D, Lopes MB, et al. cIMPACT-NOW Update 2: Diagnostic Clarifications for Diffuse Midline Glioma, H3 K27M-Mutant and Diffuse Astrocytoma/Anaplastic Astrocytoma, IDH-mutant. Acta Neuropathol (2018) 135:639-42. doi: 10.1007/s00401-018-1826-y

24. Le Rhun E, Seoane J, Salzet M, Soffietti R, Weller M. Liquid Biopsies for Diagnosing and Monitoring Primary Tumors of the Central Nervous System. Cancer Lett (2020) 480:24-8. doi: 10.1016/j.canlet.2020.03.021

25. Mattox AK, Yan H, Bettegowda C. The Potential of Cerebrospinal FluidBased Liquid Biopsy Approaches in CNS Tumors. Neuro Oncol (2019) 21:1509-18. doi: 10.1093/neuonc/noz156

26. Li J, Zhao S, Lee M, Yin Y, Li J, Zhou Y, et al. Reliable Tumor Detection by Whole-Genome Methylation Sequencing of Cell-Free DNA in Cerebrospinal Fluid of Pediatric Medulloblastoma. Sci Adv (2020) 6(42): eabb5427. doi: 10.1126/sciadv.abb5427

27. Hoshino A, Kim HS, Bojmar L, Gyan KE, Cioffi M, Hernandez J, et al. Extracellular Vesicle and Particle Biomarkers Define Multiple Human Cancers. Cell (2020) 182:1044-61.e18. doi: 10.1016/j.cell.2020.07.009

28. Tang K, Gardner S, Snuderl M. The Role of Liquid Biopsies in Pediatric Brain Tumors. J Neuropathol Exp Neurol (2020) 79:934-40. doi: 10.1093/ jnen/nlaa068

29. Zakaria R, Weinberg JS. Challenges Associated With Reoperation in Patients With Glioma. Neurosurg Clin N Am (2021) 32:129-35. doi: 10.1016/ j.nec.2020.09.004

30. Zhao YH, Wang ZF, Pan ZY, Peus D, Delgado-Fernandez J, Pallud J, et al. A Meta-Analysis of Survival Outcomes Following Reoperation in Recurrent Glioblastoma: Time to Consider the Timing of Reoperation. Front Neurol (2019) 10:286. doi: 10.3389/fneur.2019.00286

31. Vogelbaum MA, Krivosheya D, Borghei-Razavi H, Sanai N, Weller M, Wick W, et al. Phase 0 and Window of Opportunity Clinical Trial Design in Neuro-Oncology: A RANO Review. Neuro Oncol (2020) 22:1568-79. doi: 10.1093/neuonc/noaa149

32. Ellingson BM, Brown MS, Boxerman JL, Gerstner ER, Kaufmann TJ, Cole PE, et al. Radiographic Read Paradigms and the Roles of the Central Imaging Laboratory in Neuro-Oncology Clinical Trials. Neuro Oncol (2021) 23 (2):189-98. doi: 10.1093/neuonc/noaa253

33. Wen PY, Macdonald DR, Reardon DA, Cloughesy TF, Sorensen AG, Galanis E, et al. Updated Response Assessment Criteria for High-Grade Gliomas: Response Assessment in Neuro-Oncology Working Group. J Clin Oncol (2010) 28:1963-72. doi: 10.1200/JCO.2009.26.3541

34. Okada H, Weller M, Huang R, Finocchiaro G, Gilbert MR, Wick W, et al. Immunotherapy Response Assessment in Neuro-Oncology: A Report of the RANO Working Group. Lancet Oncol (2015) 16:e534-42. doi: 10.1016/ S1470-2045(15)00088-1

35. Cooney TM, Cohen KJ, Guimaraes CV, Dhall G, Leach J, Massimino M, et al. Response Assessment in Diffuse Intrinsic Pontine Glioma: Recommendations From the Response Assessment in Pediatric NeuroOncology (RAPNO) Working Group. Lancet Oncol (2020) 21:e330-6. doi: 10.1016/S1470-2045(20)30166-2

36. Erker C, Tamrazi B, Poussaint TY, Mueller S, Mata-Mbemba D, Franceschi E, et al. Response Assessment in Paediatric High-Grade Glioma: Recommendations From the Response Assessment in Pediatric NeuroOncology (RAPNO) Working Group. Lancet Oncol (2020) 21:e317-29. doi: 10.1016/S1470-2045(20)30173-X

37. Fangusaro J, Witt O, Hernaiz Driever P, Bag AK, de Blank P, Kadom N, et al. Response Assessment in Paediatric Low-Grade Glioma: Recommendations From the Response Assessment in Pediatric Neuro-Oncology (RAPNO) Working Group. Lancet Oncol (2020) 21:e305-16. doi: 10.1016/S1470-2045 (20)30064-4

38. Mennes M, Biswal BB, Castellanos FX, Milham MP. Making Data Sharing Work: The FCP/INDI Experience. Neuroimage (2013) 82:683-91. doi: 10.1016/j.neuroimage.2012.10.064

39. Milham MP, Craddock RC, Son JJ, Fleischmann M, Clucas J, Xu H, et al. Assessment of the Impact of Shared Brain Imaging Data on the Scientific Literature. Nat Commun (2018) 9:2818. doi: 10.1038/s41467-018-04976-1
40. Poline JB, Breeze JL, Ghosh S, Gorgolewski K, Halchenko YO, Hanke M, et al. Data Sharing in Neuroimaging Research. Front Neuroinform (2012) 6:9. doi: 10.3389/fninf.2012.00009

41. Sheller MJ, Edwards B, Reina GA, Martin J, Pati S, Kotrotsou A, et al. Federated Learning in Medicine: Facilitating Multi-Institutional Collaborations Without Sharing Patient Data. Sci (2020) Rep 10:12598. doi: 10.1038/s41598-020-69250-1

42. Lohmann P, Elahmadawy MA, Gutsche R, Werner JM, Bauer EK, Ceccon G, et al. Fet PET Radiomics for Differentiating Pseudoprogression From Early Tumor Progression in Glioma Patients Post-Chemoradiation. Cancers (Basel) (2020) 12(12):3835. doi: 10.3390/cancers 12123835

43. Lohmann P, Galldiks N, Kocher M, Heinzel A, Filss CP, Stegmayr C, et al. Radiomics in Neuro-Oncology: Basics, Workflow, and Applications. Methods (2021) 188:112-21. doi: 10.1016/j.ymeth.2020.06.003

44. Pati S, Verma R, Akbari H, Bilello M, Hill VB, Sako C, et al. Reproducibility Analysis of Multi-Institutional Paired Expert Annotations and Radiomic Features of the Ivy Glioblastoma Atlas Project (Ivy GAP) Dataset. Med Phys (2020) 47(12):6039-52. doi: 10.1002/mp.14556

45. Baid U, Rane SU, Talbar S, Gupta S, Thakur MH, Moiyadi A, et al. Overall Survival Prediction in Glioblastoma With Radiomic Features Using Machine Learning. Front Comput Neurosci (2020) 14:61. doi: 10.3389/ fncom.2020.00061

46. Yan J, Liu L, Wang W, Zhao Y, Li KK, Li K, et al. Radiomic Features From Multi-Parameter Mri Combined With Clinical Parameters Predict Molecular Subgroups in Patients With Medulloblastoma. Front Oncol (2020) 10:558162. doi: 10.3389/fonc.2020.558162

47. Zhou H, Hu R, Tang O, Hu C, Tang L, Chang K, et al. Automatic Machine Learning to Differentiate Pediatric Posterior Fossa Tumors on Routine $\mathrm{Mr}$ Imaging. AJNR Am J Neuroradiol (2020) 41:1279-85. doi: 10.3174/ ajnr.A6621

48. Davatzikos C, Barnholtz-Sloan JS, Bakas S, Colen R, Mahajan A, Quintero $\mathrm{CB}$, et al. AI-Based Prognostic Imaging Biomarkers for Precision NeuroOncology: The ReSPOND Consortium. Neuro Oncol (2020) 22:886-8. doi: 10.1093/neuonc/noaa045

49. Hadjipanayis CG, Stummer W. 5-ALA and FDA Approval for Glioma Surgery. J Neurooncol (2019) 141:479-86. doi: 10.1007/s11060-019-03098-y

50. Orillac C, Stummer W, Orringer DA. Fluorescence Guidance and Intraoperative Adjuvants to Maximize Extent of Resection. Neurosurgery (2020) nyaa475. doi: 10.1093/neuros/nyaa475

51. Hollon TC, Lewis S, Pandian B, Niknafs YS, Garrard MR, Garton H, et al. Rapid Intraoperative Diagnosis of Pediatric Brain Tumors Using Stimulated Raman Histology. Cancer Res (2018) 78:278-89. doi: 10.1158/00085472.CAN-17-1974

52. Orringer DA, Pandian B, Niknafs YS, Hollon TC, Boyle J, Lewis S, et al. Rapid Intraoperative Histology of Unprocessed Surgical Specimens Via Fibre-Laser-Based Stimulated Raman Scattering Microscopy. Nat BioMed Eng (2017) 1:0027. doi: 10.1038/s41551-016-0027

53. Ishida J, Alli S, Bondoc A, Golbourn B, Sabha N, Mikloska K, et al. MRIGuided Focused Ultrasound Enhances Drug Delivery in Experimental Diffuse Intrinsic Pontine Glioma. J Control Release (2020) 330:1034-45. doi: $10.1016 /$ j.jconrel.2020.11.010

54. Wu SK, Tsai CL, Huang Y, Hynynen K. Focused Ultrasound and Microbubbles-Mediated Drug Delivery to Brain Tumor. Pharmaceutics (2020) 13(1):15. doi: 10.3390/pharmaceutics 13010015

55. Bailey DL, Hennessy TM, Willowson KP, Henry EC, Chan DL, Aslani A, et al. In Vivo Measurement and Characterization of a Novel Formulation of [(177)Lu]-DOTA-Octreotate. Asia Ocean J Nucl Med Biol (2016) 4:30-7. doi: 10.7508/aojnmb.2016.04.005

56. Cordova C, Kurz SC. Advances in Molecular Classification and Therapeutic Opportunities in Meningiomas. Curr Oncol (2020) Rep 22:84. doi: 10.1007/ s11912-020-00937-4

57. Gross JP, Powell S, Zelko F, Hartsell W, Goldman S, Fangusaro J, et al. Improved Neuropsychological Outcomes Following Proton Therapy Relative to X-ray Therapy for Pediatric Brain Tumor Patients. Neuro Oncol (2019) 21:934-43. doi: 10.1093/neuonc/noz070

58. Kahalley LS, Douglas Ris M, Mahajan A, Fatih Okcu M, Chintagumpala M, Paulino AC, et al. Prospective, Longitudinal Comparison of Neurocognitive Change in Pediatric Brain Tumor Patients Treated With Proton 
Radiotherapy Versus Surgery Only. Neuro Oncol (2019) 21:809-18. doi: 10.1093/neuonc/noz041

59. Kahalley LS, Peterson R, Ris MD, Janzen L, Okcu MF, Grosshans DR, et al. Superior Intellectual Outcomes After Proton Radiotherapy Compared With Photon Radiotherapy for Pediatric Medulloblastoma. J Clin Oncol (2020) 38:454-61. doi: 10.1200/JCO.19.01706

60. Indelicato DJ, Rotondo RL, Uezono H, Sandler ES, Aldana PR, Ranalli NJ, et al. Outcomes Following Proton Therapy for Pediatric Low-Grade Glioma. Int J Radiat Oncol Biol Phys (2019) 104:149-56. doi: 10.1016/ j.ijrobp.2019.01.078

61. Eaton BR, Goldberg S, Tarbell NJ, Lawell MP, Gallotto SL, Weyman EA, et al. Long-Term Health-Related Quality of Life in Pediatric Brain Tumor Survivors Receiving Proton Radiotherapy At $<4$ Years of Age. Neuro Oncol (2020) 22:1379-87. doi: 10.1093/neuonc/noaa042

62. Smith WL, Smith CD, Patel S, Eisenstat DD, Quirk S, Mackenzie M, et al. What Conditions Make Proton Beam Therapy Financially Viable in Western Canada? Cureus (2018) 10:e3644. doi: 10.7759/cureus.3644

63. Tsang DS, Patel S. Proton Beam Therapy for Cancer. CMAJ (2019) 191: E664-6. doi: 10.1503/cmaj.190008

64. Malouff TD, Mahajan A, Krishnan S, Beltran C, Seneviratne DS, Trifiletti DM. Carbon Ion Therapy: A Modern Review of an Emerging Technology. Front Oncol (2020) 10:82. doi: 10.3389/fonc.2020.00082

65. Eaton BR, Yock TI. Radiation for Pediatric Low-Grade Gliomas: Who Will Benefit and How Late is Soon Enough? Neuro Oncol (2020) 22:1068-9. doi: 10.1093/neuonc/noaa144

66. Noll KR, Bradshaw ME, Parsons MW, Dawson EL, Rexer J, Wefel JS. Monitoring of Neurocognitive Function in the Care of Patients With Brain Tumors. Curr Treat Options Neurol (2019) 21:33. doi: 10.1007/s11940-0190573-2

67. Noll KR, Sullaway CM, Wefel JS. Depressive Symptoms and Executive Function in Relation to Survival in Patients With Glioblastoma. J Neurooncol (2019) 142:183-91. doi: 10.1007/s11060-018-03081-z

68. Stupp R, Taillibert S, Kanner A, Read W, Steinberg D, Lhermitte B, et al. Effect of Tumor-Treating Fields Plus Maintenance Temozolomide vs Maintenance Temozolomide Alone on Survival in Patients With Glioblastoma: A Randomized Clinical Trial. JAMA (2017) 318:2306-16. doi: $10.1001 /$ jama.2017.18718

69. Stupp R, Wong ET, Kanner AA, Steinberg D, Engelhard H, Heidecke V, et al. NovoTTF-100A Versus Physician's Choice Chemotherapy in Recurrent Glioblastoma: A Randomised Phase III Trial of a Novel Treatment Modality. Eur J Cancer (2012) 48:2192-202. doi: 10.1016/j.ejca.2012.04.011

70. Wick W. Ttfields: Where Does All the Skepticism Come From? Neuro Oncol (2016) 18:303-5. doi: 10.1093/neuonc/now012

71. Ceresoli GL, Aerts JG, Dziadziuszko R, Ramlau R, Cedres S, van Meerbeeck JP, et al. Tumour Treating Fields in Combination With Pemetrexed and Cisplatin or Carboplatin as First-Line Treatment for Unresectable Malignant Pleural Mesothelioma (STELLAR): A Multicentre, Single-Arm Phase 2 Trial. Lancet Oncol (2019) 20:1702-9. doi: 10.1016/S1470-2045(19)30532-7

72. Stupp R, Mason WP, van den Bent MJ, Weller M, Fisher B, Taphoorn MJ, et al. R. European Organisation for, T. Treatment of Cancer Brain, G. Radiotherapy, and G. National Cancer Institute of Canada Clinical Trials, Radiotherapy Plus Concomitant and Adjuvant Temozolomide for Glioblastoma. N Engl J Med (2005) 352:987-96. doi: 10.1056/nejmoa043330

73. McAleenan A, Kelly C, Spiga F, Kernohan A, Cheng HY, Dawson S, et al. Prognostic Value of Test(s) for O6-methylguanine-DNA Methyltransferase (MGMT) Promoter Methylation for Predicting Overall Survival in People With Glioblastoma Treated With Temozolomide. Cochrane Database Syst Rev (2021) 3:Cd013316. doi: 10.1002/14651858.CD013316.pub2

74. Mellinghoff IK, Ellingson BM, Touat M, Maher E, De La Fuente MI, Holdhoff $\mathrm{M}$, et al. Ivosidenib in Isocitrate Dehydrogenase 1-Mutated Advanced Glioma. J Clin Oncol (2020) 38:3398-406. doi: 10.1200/ JCO.19.03327

75. Frattini V, Pagnotta SM, Tala JJ, Russo MV, Lee SB, Garofano L, et al. A Metabolic Function of FGFR3-TACC3 Gene Fusions in Cancer. Nature (2018) 553:222-7. doi: 10.1038/nature25171

76. Albert CM, Davis JL, Federman N, Casanova M, Laetsch TW. Trk Fusion Cancers in Children: A Clinical Review and Recommendations for Screening. J Clin Oncol (2019) 37:513-24. doi: 10.1200/JCO.18.00573
77. Wang Y, Long P, Wang Y, Ma W, Fusions NTRK. And TRK Inhibitors: Potential Targeted Therapies for Adult Glioblastoma. Front Oncol (2020) 10:593578. doi: 10.3389/fonc.2020.593578

78. Nobre L, Zapotocky M, Ramaswamy V, Ryall S, Bennett J, Alderete D, et al. Outcomes of BRAF V600e Pediatric Gliomas Treated With Targeted Braf Inhibition. JCO Precis Oncol (2020) 4:PO.19.00298. doi: 10.1200/po.19.00298

79. Sachamitr P, Ho JC, Ciamponi FE, Ba-Alawi W, Coutinho FJ, Guilhamon P, et al. PRMT5 Inhibition Disrupts Splicing and Stemness in Glioblastoma. Nat Commun (2021) 12:979. doi: 10.1038/s41467-021-21204-5

80. Theeler BJ, Dalal Y, Monje M, Shilatifard A, Suva ML, Aboud O, et al. NciConnect: Comprehensive Oncology Network Evaluating Rare Cns TumorsHistone Mutated Midline Glioma Workshop Proceedings. Neurooncol Adv (2020) 2:vdaa007. doi: 10.1093/noajnl/vdaa007

81. Anastas JN, Zee BM, Kalin JH, Kim M, Guo R, Alexandrescu S, et al. RePrograming Chromatin With a Bifunctional Lsd1/Hdac Inhibitor Induces Therapeutic Differentiation in DIPG. Cancer Cell (2019) 36:528-44.e10. doi: 10.1016/j.ccell.2019.09.005

82. Vanan MI, Underhill DA, Eisenstat DD. Targeting Epigenetic Pathways in the Treatment of Pediatric Diffuse (High Grade) Gliomas. Neurotherapeutics (2017) 14:274-83. doi: 10.1007/s13311-017-0514-2

83. Michealraj KA, Kumar SA, Kim LJY, Cavalli FMG, Przelicki D, Wojcik JB, et al. Metabolic Regulation of the Epigenome Drives Lethal Infantile Ependymoma. Cell (2020) 181:1329-45.e24. doi: 10.1016/j.cell.2020.04.047

84. Panwalkar P, Clark J, Ramaswamy V, Hawes D, Yang F, Dunham C, et al. Immunohistochemical Analysis of H3K27me3 Demonstrates Global Reduction in Group-a Childhood Posterior Fossa Ependymoma and is a Powerful Predictor of Outcome. Acta Neuropathol (2017) 134:705-14. doi: 10.1007/s00401-017-1752-4

85. Lee EQ, Weller M, Sul J, Bagley SJ, Sahebjam S, van den Bent M, et al. Optimizing Eligibility Criteria and Clinical Trial Conduct to Enhance Clinical Trial Participation for Primary Brain Tumor Patients. Neuro Oncol (2020) 22:601-12. doi: 10.1093/neuonc/noaa015

86. Molinari E, Mendoza TR, Gilbert MR. Opportunities and Challenges of Incorporating Clinical Outcome Assessments in Brain Tumor Clinical Trials. Neurooncol Pract (2019) 6:81-92. doi: 10.1093/nop/npy032

87. Vanderbeek AM, Ventz S, Rahman R, Fell G, Cloughesy TF, Wen PY, et al. To Randomize, or Not to Randomize, That is the Question: Using Data From Prior Clinical Trials to Guide Future Designs. Neuro Oncol (2019) 21:1239-49. doi: 10.1093/neuonc/noz097

88. Alexander BM, Ba S, Berger MS, Berry DA, Cavenee WK, Chang SM, et al. Adaptive Global Innovative Learning Environment for Glioblastoma: Gbm Agile. Clin Cancer Res (2018) 24:737-43. doi: 10.1158/1078-0432.CCR-170764

89. Chuntova P, Chow F, Watchmaker P, Galvez M, Heimberger AB, Newell EW, et al. Unique Challenges for Glioblastoma Immunotherapy Discussions Across Neuro-Oncology and non-Neuro-Oncology Experts in Cancer Immunology. Neuro Oncol (2021) 23(3):356-75. doi: 10.1093/ neuonc/noaa277

90. Montoya ML, Kasahara N, Okada H. Introduction to Immunotherapy for Brain Tumor Patients: Challenges and Future Perspectives. Neurooncol Pract (2020) 7:465-76. doi: 10.1093/nop/npaa007

91. Kwok D, Okada H. T-Cell Based Therapies for Overcoming Neuroanatomical and Immunosuppressive Challenges Within the Glioma Microenvironment. J Neurooncol (2020) 147:281-95. doi: 10.1007/s11060020-03450-7

92. Zhu Z, Mesci P, Bernatchez JA, Gimple RC, Wang X, Schafer ST, et al. Zika Virus Targets Glioblastoma Stem Cells Through a SOX2-Integrin Alphavbeta5 Axis. Cell Stem Cell (2020) 26:187-204.e10. doi: 10.1016/ j.stem.2019.11.016

93. Desjardins A, Gromeier M, Herndon JE, Beaubier N, Bolognesi DP, Friedman AH, et al. Recurrent Glioblastoma Treated With Recombinant Poliovirus. N Engl J Med (2018) 379:150-61. doi: 10.1056/NEJMoa1716435

94. Nair S, Mazzoccoli L, Jash A, Govero J, Bais SS, Hu T, et al. Zika Virus Oncolytic Activity Requires CD8+ T Cells and is Boosted by Immune Checkpoint Blockade. JCI Insight (2021) 6(1):e144619. doi: 10.1172/ jci.insight. 144619

95. Wirsching HG, Zhang H, Szulzewsky F, Arora S, Grandi P, Cimino PJ, et al. Arming oHSV With ULBP3 Drives Abscopal Immunity in Lymphocyte- 
Depleted Glioblastoma. JCI Insight (2019) 4(13):e128217. doi: 10.1172/ jci.insight. 128217

96. Chiocca EA, Nassiri F, Wang J, Peruzzi P, Zadeh G. Viral and Other Therapies for Recurrent Glioblastoma: Is a 24-Month Durable Response Unusual? Neuro Oncol (2019) 21:14-25. doi: 10.1093/neuonc/noy170

97. Brown NF, Ng SM, Brooks C, Coutts T, Holmes J, Roberts C, et al. Randomised Study of Ipilimumab With Temozolomide Versus Temozolomide Alone After Surgery and Chemoradiotherapy in Patients With Recently Diagnosed Glioblastoma: The Ipi-Glio Trial Protocol. BMC Cancer (2020) 20:198. doi: 10.1186/s12885-020-6624-y

98. Gedeon PC, Champion CD, Rhodin KE, Woroniecka K, Kemeny HR, Bramall AN, et al. Checkpoint Inhibitor Immunotherapy for Glioblastoma: Current Progress, Challenges and Future Outlook. Expert Rev Clin Pharmacol (2020) 13:1147-58. doi: 10.1080/17512433.2020.1817737

99. Khasraw M, Reardon DA, Weller M, Sampson JH. Pd-1 Inhibitors: do They Have a Future in the Treatment of Glioblastoma? Clin Cancer Res (2020) 26:5287-96. doi: 10.1158/1078-0432.CCR-20-1135

100. Theruvath J, Sotillo E, Mount CW, Graef CM, Delaidelli A, Heitzeneder S, et al. Locoregionally Administered B7-H3-targeted Car T Cells for Treatment of Atypical Teratoid/Rhabdoid Tumors. Nat Med (2020) 26:712-9. doi: 10.1038/s41591-020-0821-8

101. Donovan LK, Delaidelli A, Joseph SK, Bielamowicz K, Fousek K, Holgado BL, et al. Locoregional Delivery of CAR T Cells to the Cerebrospinal Fluid for Treatment of Metastatic Medulloblastoma and Ependymoma. Nat Med (2020) 26:720-31. doi: 10.1038/s41591-020-0827-2

102. Patterson JD, Henson JC, Breese RO, Bielamowicz KJ, Rodriguez A. Car T Cell Therapy for Pediatric Brain Tumors. Front Oncol (2020) 10:1582. doi: $10.3389 /$ fonc. 2020.01582

103. Haydar D, Houke H, Chiang J, Yi Z, Ode Z, Caldwell K, et al. Cell Surface Antigen Profiling of Pediatric Brain Tumors: B7-H3 is Consistently
Expressed and can be Targeted Via Local or Systemic CAR T-Cell Delivery. Neuro Oncol (2020) noaa278. doi: 10.1093/neuonc/noaa278

104. Bouffet E, Larouche V, Campbell BB, Merico D, de Borja R, Aronson M, et al. Immune Checkpoint Inhibition for Hypermutant Glioblastoma Multiforme Resulting From Germline Biallelic Mismatch Repair Deficiency. J Clin Oncol (2016) 34:2206-11. doi: 10.1200/JCO.2016.66.6552

105. Reardon DA, Brandes AA, Omuro A, Mulholland P, Lim M, Wick A, et al. Effect of Nivolumab vs Bevacizumab in Patients With Recurrent Glioblastoma: The CheckMate 143 Phase 3 Randomized Clinical Trial. JAMA Oncol (2020) 6:1003-10. doi: 10.1001/jamaoncol.2020.1024

106. Liu EK, Sulman EP, Wen PY, Kurz SC. Novel Therapies for Glioblastoma. Curr Neurol Neurosci Rep (2020) 20:19. doi: 10.1007/s11910-020-01042-6

107. Shanmugavadivel D, Liu JF, Murphy L, Wilne S, Walker D. And HeadSmart, Accelerating Diagnosis for Childhood Brain Tumours: An Analysis of the HeadSmart UK Population Data. Arch Dis Child (2020) 105:355-62. doi: 10.1136/archdischild-2018-315962

108. Liu EK, Yu S, Sulman EP, Kurz SC. Racial and Socioeconomic Disparities Differentially Affect Overall and Cause-Specific Survival in Glioblastoma. J Neurooncol (2020) 149:55-64. doi: 10.1007/s11060-020-03572-y

Conflict of Interest: The authors declare that the research was conducted in the absence of any commercial or financial relationships that could be construed as a potential conflict of interest.

Copyright $\odot 2021$ Sulman and Eisenstat. This is an open-access article distributed under the terms of the Creative Commons Attribution License (CC BY). The use, distribution or reproduction in other forums is permitted, provided the original author(s) and the copyright owner(s) are credited and that the original publication in this journal is cited, in accordance with accepted academic practice. No use, distribution or reproduction is permitted which does not comply with these terms. 